\title{
SUBSTRATO NO ENRAIZAMENTO DE ESTACAS PROVENIENTES DE MUDAS DE Schizolobium parahyba var. amazonicum
}

\author{
Clenes Cunha Lima¹, Selma Toyoko Ohashi²
}

1 Professora MsC. Universidade Federal Rural da Amazônia (clenes.cunha@ufra.edu.br) Pará-Brasil

2 Professora Dra. Universidade Federal Rural da Amazônia Pará-Brasil

\section{Recebido em: 08/04/2016 - Aprovado em: 30/05/2016 - Publicado em: 20/06/2016 DOI: 10.18677/Enciclopedia_Biosfera_2016_112}

\begin{abstract}
RESUMO
Objetivou-se avaliar a influência do substrato e tempo de avaliação no enraizamento de estacas provenientes de mudas de Schizolobium parahyba var. amazonicum. Foram produzidas mudas e obtidas estacas que foram imersas em solução de ácido indol-3-butírico (AIB) na concentração $3.000 \mathrm{mg} \mathrm{L}^{-1}$ durante 10 segundos e logo após, plantadas em bandejas plásticas contendo os substratos e colocadas em caixa de enraizamento. O delineamento experimental foi inteiramente casualizado, em parcela subdividida no tempo, com seis repetições e 10 estacas por parcela, com sorteio de três estacas por parcela para avaliação no tempo. Parcelas vermiculita+fibra de coco+areia lavada (2:1:2); vermiculita+fibra de coco (1:1) e vermiculita+areia (1:1); subparcelas: 10, 15, 20, 25 e 30 dias. As variáveis analisadas foram: Percentagem de estacas enraizadas, estacas brotadas, estacas com calos, número médio de raiz, comprimento da maior raiz e comprimento do broto. A vermiculita+fibra de coco e vermiculita+fibra de coco+areia apresentaram os melhores resultados e o ponto máximo de enraizamento $(80$ e $85 \%$, respectivamente) ocorreu aos 20 dias, sem incremento significativo a partir desse período. Para percentual de estacas com calos, estacas com brotos e comprimento de broto, houve diferença significativa para o tempo apenas na primeira avaliação (10 dias), não apresentando, a partir desse período, respostas significativas.
\end{abstract}

PALAVRAS-CHAVE: Estaquia, rizogênese, propagação vegetativa

\section{SUBSTRATE ON ROOTING OF CUTTINGS OF Schizolobium parahyba var. amazonicum FROM SEEDLINGS}

\begin{abstract}
Objective was evaluate the influence of substrate and time on rooting of cuttings from seedlings Schizolobium parahyba var. amazonicum. Were produced for both seedlings and cuttings obtained which were immersed in a solution of indole-3butyric acid (IBA) at a concentration of $3000 \mathrm{Mg} \mathrm{L}^{-1}$ for 10 seconds and after, planted in plastic trays containing the substrates and placed in rooting box. The experimental design was completely randomized in split plot in time, six repetitions and 10 cuttings per plot. The plots: vermiculite+coconut fiber+washed sand (2:1:1); coconut fiber+vermiculite (1:1) and vermiculite+sand (1:1); subplots: 10, 15, 20, 25 and 30 days. The variables analyzed were: Percentage of rooted cuttings, sprouting cuttings, calluses cuttings, average number of roots, length of roots and length of the sprout. ENCICLOPÉDIA BIOSFERA, Centro Científico Conhecer - Goiânia, v.13 n.23; p. 12702016
\end{abstract}


That vermiculite+coconut fiber and coconut fiber+sand showed the best results and that the point of maximum rooting occurs at 20 days, with no significant increase from that period. For the percentage callus cuttings, sprouting and bud length there were significant differences for the time only the first assessment (10 days), with responses from that period were, statistically equal.

KEYWORDS: Cutting, rhizogenesis, vegetation propagation

\section{INTRODUÇÃO}

A produção de mudas por meio da propagação vegetativa é um processo frequente e natural em muitas espécies frutíferas, no entanto, a sua aplicação em espécies florestais nativas ainda precisa de avanços quanto ao aprimoramento do processo. XAVIER et al. (2009) destacam que o crescente aumento pelo interesse desse processo é decorrente tanto das vantagens dos métodos utilizados quanto da possibilidade de contornar problemas de determinadas doenças, heterogeneidade e produtividade dos plantios florestais.

A estaquia é o método mais utilizado para as espécies florestais (XAVIER et al. 2009), uma forma simples e prática de propagação, que consiste em destacar uma parte da planta e colocá-la em substrato adequado para que surjam raízes e se origine uma nova planta. Segundo DIAS et al. (2012) esta técnica pode ser utilizada para fins comerciais, assim como auxiliar no resgate e conservação de recursos genéticos florestais.

Portanto, para o sucesso desta técnica torna-se necessário atentar para determinados fatores que podem influenciar negativa ou positivamente à formação de raízes. Condições adequadas de aeração e boa drenagem para o suporte da estaca é um fator determinante em todo o processo que envolve o enraizamento, possibilitando deste modo à sobrevivência e desempenho da futura planta.

Para GARAY et al. (2014), os substratos possuem vantagens e desvantagens. Não há um substrato ideal. Desta forma, a escolha de um bom material depende das características da cultura e do custo para aquisição, tornandose necessário testar diferentes substratos ou misturas de substratos para cada espécie.

A vermiculita é um dos mais utilizados para o enraizamento de estacas herbáceas e semi-lenhosas devido à elevada porosidade e boa retenção de umidade. Possui pequena variação de características químicas e físicas, ser praticamente isenta de patógenos, plantas invasoras e insetos, e é encontrada facilmente em casas de comercialização de produtos agrícolas (HARTMANN et al. 2011), podendo ser utilizada isolada ou em combinação à outros materiais.

Schizolobium parahyba var. amazonicum (Huber ex Ducke) Barneby, o paricá, está entre o grupo de espécies florestais nativas da Amazônia que estão na fase de aperfeiçoamento do processo de propagação vegetativa, nos quais incluem o processo rizogênico, ou seja, compreender os fatores que interferem na formação e desenvolvimento de raízes nas estacas. Forte representante do grupo de espécies com alto valor madeireiro destaca-se pelo rápido crescimento e adaptabilidade em condições adversas de solo (DUCKE, 1949). No entanto, é preciso avançar em relação a propagação para favorecer os estabelecimentos de plantios.

Nesse enfoque, objetivou-se avaliar diferentes substratos e tempos de avaliação no enraizamento de estacas provenientes de mudas de paricá, visando definir o melhor substrato para uso no sistema de produção de mudas de estacas juvenis da espécie. 


\section{MATERIAL E MÉTODOS}

O experimento foi conduzido em casa de vegetação localizada nas coordenadas geográficas de $01^{\circ} 27^{\prime} 25^{\prime \prime}$ latitude $S$ e $48^{\circ} 26^{\prime} 48^{\prime \prime}$ longitude W, Belém, Pará. $O$ ambiente de plantio das estacas foi uma caixa de enraizamento mantida em ambiente de casa de vegetação coberta com telhas semitransparentes. A caixa foi confeccionada em madeira e revestida com plástico transparente em todos os lados. Tal construção propiciou as condições favoráveis ao enraizamento das estacas, no qual foram colocadas bandejas plásticas com os substratos a serem avaliados.

As plantas de paricá utilizadas para obtenção das estacas apresentavam quatro meses de idade. As estacas foram obtidas a partir da região basal da muda com tamanho médio de $12 \mathrm{~cm}$ de comprimento e $4,0 \mathrm{~mm}$ de diâmetro. O preparo das estacas consistiu em um corte em bisel na base e ápice das estacas com a finalidade de aumentar a área de absorção da solução de enraizamento e evitar possível acúmulo de agua que poderia comprometer a sanidade das estacas, respectivamente. Deixou-se um par de folhas, reduzidas a metade. Para evitar perda de umidade, as estacas foram armazenadas em recipiente com água até o momento do plantio.

Para o preparo da solução de AIB (ácido indolbutírico) a $3.000 \mathrm{mg} \mathrm{L}^{-1}$ foi feita uma diluição do regulador (em forma de pó) em álcool etílico (98 ${ }^{\circ} \mathrm{GL}$ ) de $50 \mathrm{~mL}$ e completado o volume com água destilada até $100 \mathrm{~mL}$. Nessa solução foram imersas as bases das estacas durante 10 segundos e em seguida, foram colocadas em bandejas plásticas contendo os substratos a serem testados.

$O$ delineamento experimental adotado foi inteiramente casualizado, em parcela subdividida no tempo, com seis repetições e 10 estacas por parcela. As parcelas constituíram-se das diferentes composições de substratos: vermiculita+fibra de coco+areia lavada $(\mathrm{V}+\mathrm{FC}+\mathrm{A})-2: 1: 1 \mathrm{v}$; vermiculita + fibra de coco $(\mathrm{V}+\mathrm{FC})-1: 1 \mathrm{v}$ e vermiculita+areia $(\mathrm{V}+\mathrm{A})-1: 1 \mathrm{v}$; e as subparcelas representada pelo tempo de avaliação (10, 15, 20, 25 e 30 dias após a implantação do experimento). Para cada tempo de avaliação foram sorteadas três estacas em cada parcela para cada substrato, totalizando 18 plantas por avaliação, para obtenção dos dados.

As variáveis mensuradas consistiram em: percentagem de estacas enraizadas (\%EE), número médio de raizes por estaca (NMR), comprimento da maior raiz (CMR), percentagem de estacas com calos (\%ECC), percentagem de estacas brotadas (\%EB) e comprimento do broto (CB).

Procederam-se à transformação dos dados com garantias dos pressupostos de normalidade e homogeneidade de variâncias, necessários para aplicação da Análise de Variância (Anova). Os valores em percentagem foram transformados por meio da fórmula arcsen $\sqrt{ } \mathrm{x} / 100$. Os dados de número e comprimento foram transformados em $\sqrt{x}+1$, onde $x$ é o valor da variável obtida.

As médias do fator qualitativo com efeitos significativos foram comparadas pelo teste de Tukey a $5 \%$ de probabilidade e do fator quantitativo mediante análise de regressão para verificar o efeito do tempo no enraizamento e desenvolvimento da plântula.

\section{RESULTADOS E DISCUSSÃO}


As variáveis do processo rizogênico e desenvolvimento de brotações tiveram comportamento comprometido em função do substrato para: percentual de estacas enraizadas, comprimento da maior raiz e número médio de raiz. E tempo de avaliação em todas as variáveis analisadas (percentagem de estacas enraizadas, número médio de raiz, comprimento da maior raiz, percentagem de estacas com calos, percentagem de estacas brotadas e comprimento do broto CB). Também houve interação destes fatores para percentual de estacas enraizadas e comprimento da maior raiz.

As estacas apresentaram o máximo de enraizamento nos substratos vermiculita+fibra de coco e vermiculita+fibra de coco+areia aos 20 dias de avaliação, alcançando respectivamente, $85 \%$ e $80 \%$, de estacas enraizadas. Para o substrato $\mathrm{V}+\mathrm{A}$ este percentual total $(56,6 \%)$ ocorreu aos 25 dias. Para o comprimento da maior raiz aos 20 dias as estacas também tinham o tamanho máximo em comprimento, porém, este período não diferiu nos três substratos testados em comparação aos 25 e 30 dias. A avaliação realizada aos 10 e 15 dias exibiram os menores valores, com igualdade entre si nos três substratos (Tabela 1).

TABELA 1 Teste de comparação de médias dos substratos e tempo de avaliação para percentagem de estacas enraizadas, comprimento médio da raiz e número médio de raízes plantadas em três substratos: vermiculita+fibra de coco+areia $(\mathrm{V}+\mathrm{FC}+\mathrm{A})$; vermiculita+fibra de coco $(\mathrm{V}+\mathrm{FC})$ e vermiculita+areia $(V+A)$ e avaliadas em cinco períodos $(10,15,20,25$ e 30 dias)

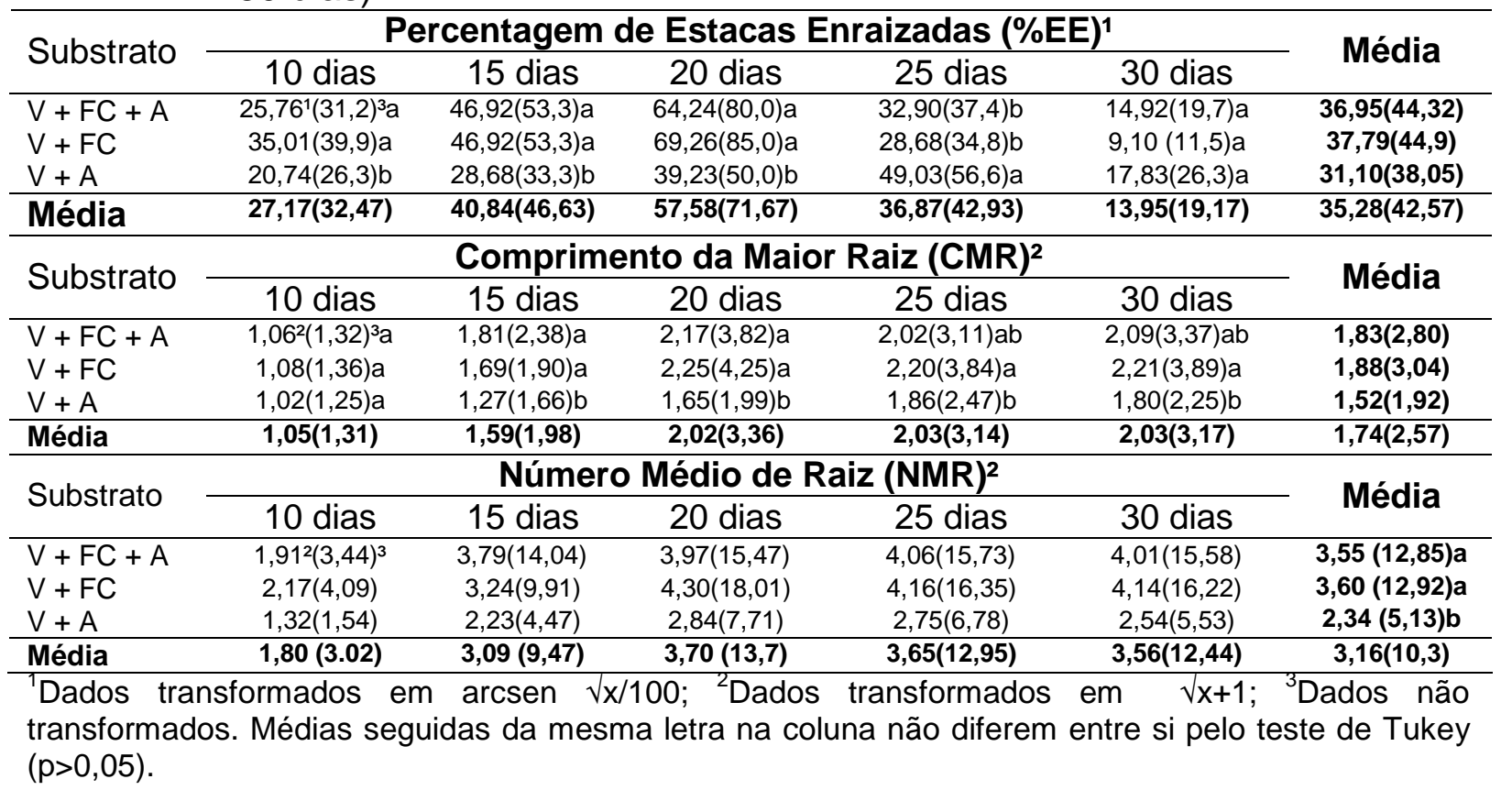

A análise de regressão efetuada mostrou significância a nível de $5 \%$ de probabilidade para substrato em função do tempo de avaliação. A análise indicou uma tendência para formação de raízes nas estacas de paricá seguindo uma curva quadrática, com o máximo enraizamento de $51,4 \%$ atingido aos 19 dias para os substratos vermiculita+fibra de coco+areia, $53,85 \%$ aos 18 dias para vermiculita+fibra de coco e $40,91 \%$ aos 21 dias para o substrato vermiculita+areia. Para comprimento da maior raiz, a regressão também mostrou este comportamento, com o máximo de tamanho da raiz, adquirido aos 24 (2,22 centímetros) e 25 dias ENCICLOPÉDIA BIOSFERA, Centro Científico Conhecer - Goiânia, v.13 n.23; p. 12732016 
(2,28 centímetros), para os substratos vermiculita+fibra de coco+areia e vermiculita+fibra de coco, respectivamente. Para vermiculita+areia, este comprimento máximo (1,80 centímetros) ocorreu aos 28 dias, com redução gradativa a partir deste período (Figuras 1 e 2).

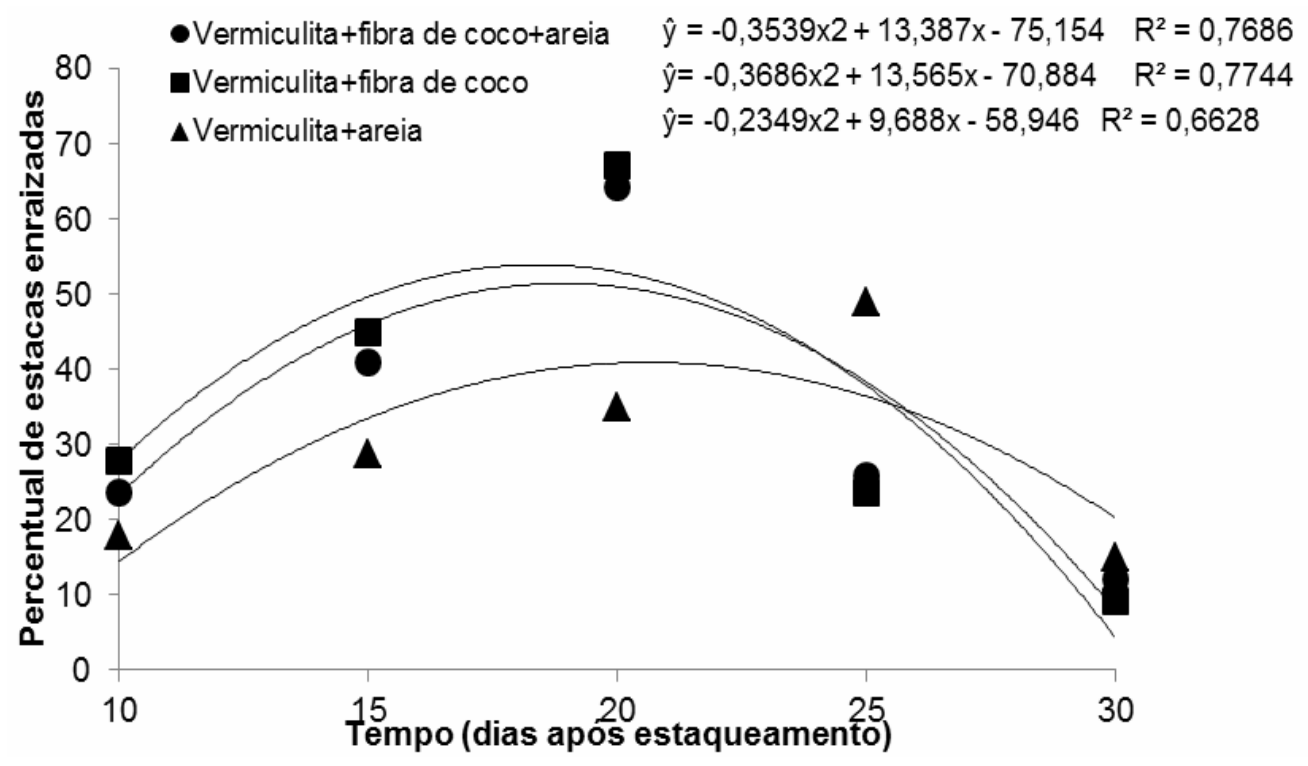

FIGURA 1 Evolução do enraizamento em estacas de paricá ao longo do tempo em três substratos

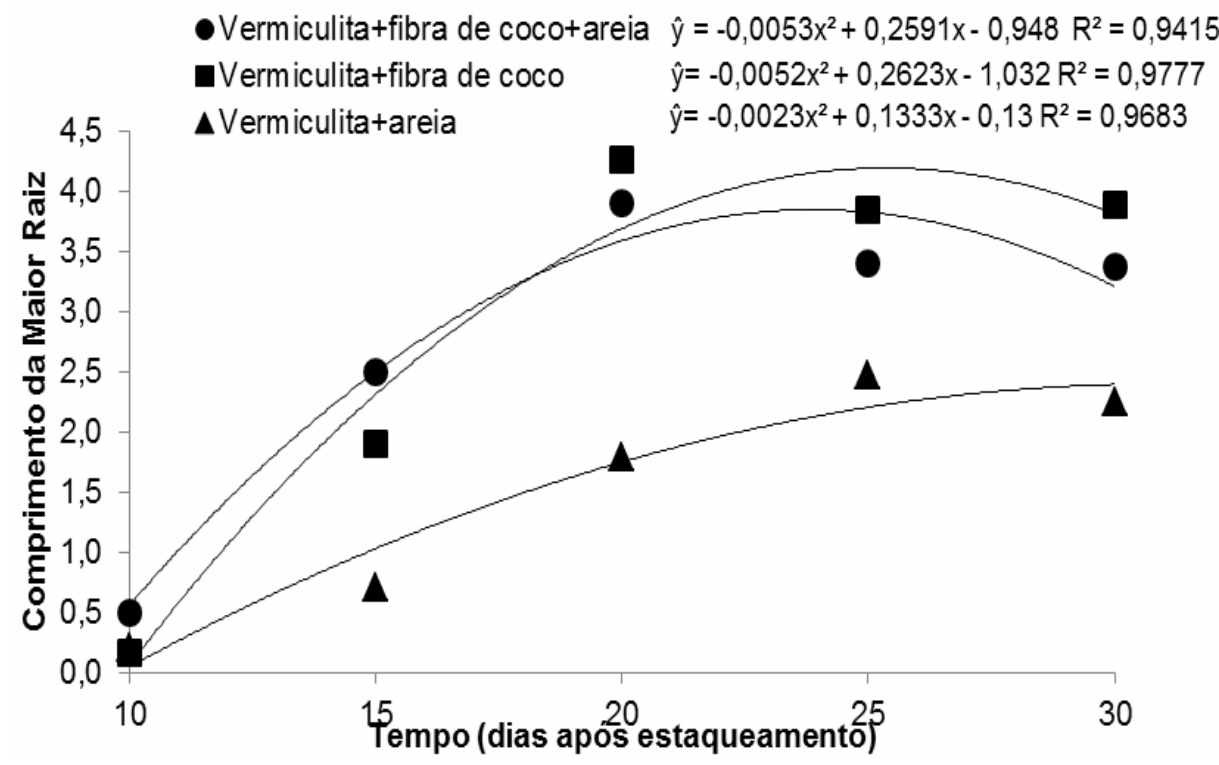

FIGURA 2 Evolução do comprimento da maior raiz em estacas de paricá ao longo do tempo em três substratos

Os tipos de substratos e o tempo para enraizamento foram fatores que comprometeram sobremaneira o processo rizogênico das estacas de paricá. 0 substrato vermiculita+fibra de coco proporcionou respostas positivas ao 
enraizamento das estacas, proporcionando os maiores percentuais de enraizamento e melhor comprimento da maior raiz.

Diversos trabalhos demonstram a eficiência da vermiculita pura ou em mistura com outros produtos como meio adequado à emissão e crescimento de raízes em estacas de diversas espécies, tais como, estacas de Litchi chinensis descritor da espécie (KOYAMA, et al. 2014); pessegueiro do gênero Okinawa (CARDOSO et al. 2011). Nestas espécies, os autores observaram que as estacas plantadas em vermiculita tiveram redução no tempo de permanência em casa de vegetação, pois a sobrevivência e enraizamento foram superiores. Na clonagem de Eucalyptus, diversos autores destacam que o substrato constituído apenas de vermiculita ou pela combinação com casca de arroz carbonizada, fibra de coco e ainda outras combinações, é o mais utilizado para propagação por estaquia desta espécie (SILVA et al., 2012; BORGES, et al. 2011).

De acordo com MARTINS et al. (2009), a vermiculita é um substrato comumente utilizado para a produção de mudas de espécies florestais. Suas vantagens estão associadas à: fácil obtenção, uniformidade na composição química e granulométrica, porosidade, capacidade de retenção de água e baixa densidade, além de ser inodoro e atóxico.

Segundo CASTOLDI et al. (2014), o componente fibra de coco tem sido uma opção de material para substrato em função das suas características físico-químicas importantes para o desenvolvimento e formação das raízes. ARAMÉNDIZ-TATIS et al. (2013) destacam ainda que o substrato contendo fibra de coco como componente, apresenta alta porosidade, alto potencial de retenção de umidade, é inerte aos fertilizantes, biodegradável e pode ser passível de esterilização. Desta forma, em combinação com a vermiculita, este componente forneceu as melhores condições, face à capacidade destes substratos em reter água, em contrapartida a areia foi menos eficiente.

O substrato $\mathrm{V}+\mathrm{A}$ (Vermiculita + Areia) propiciou as menores respostas para a formação e desenvolvimento das raízes, sendo que nesta mistura houve maiores quantidades de areia (50\%) em relação às outras duas combinações, o que pode ter favorecido estes resultados. A areia apresenta desuniformidade de retenção e distribuição de água, uma vez que a parte superior do substrato fica ressecada, não ocorrendo drenagem uniforme no ambiente e manutenção de umidade do substrato, o que pode ter prejudicado a emissão de raízes.

O substrato é um fator que afeta diretamente a formação de raízes em estacas. Conforme XAVIER et al. (2009), isso se deve as funções dos substratos, mediante sustentação das estacas durante o período de enraizamento e aeração adequada ao desenvolvimento das raízes, bem como condições de umidade e nutrição para o crescimento do sistema radicial.

Além do mais, o sistema de enraizamento deve proporcionar um bom condicionamento para que as estacas realizem o processo rizogênico. De acordo com HARTMANN et al. (2011) este processo envolve a desdiferenciação de células especificas, formação de raízes iniciais próximas ao tecido vascular, as quais tornam-se meristemáticas pela desdiferenciação, desenvolvimento de raízes iniciais e finalmente crescimento e emergência dos primórdios radiciais.

Diferentemente dos resultados obtidos neste trabalho, ENDRES et al. (2007) estudando o enraizamento de estacas de Caesalpinia echinata L. (pau-brasil), utilizaram apenas areia grossa esterilizada como substrato para enraizamento de estaca desta espécie. As primeiras experiências com enraizamento de estacas de 
matas de galeria tiveram a areia como componente no substrato utilizado, de acordo com OLIVEIRA et al. (2001). Portanto, a areia em combinação a outros produtos também é utilizada para algumas espécies, uma vez que podem contribuir com boas condições para que as estacas possam iniciar o processo de formação de raízes, além de ser um produto de baixo custo.

Observou-se neste experimento que quando houve a combinação dos três substratos vermiculita+fibra de coco+areia, o crescimento e desenvolvimento das estacas foi semelhante à combinação de vermiculita+fibra de coco, com uma proporção de 2:1:1, ou seja, há um equilíbrio entre a fibra de coco e areia neste substrato. Desta forma, pode-se inferir que estes dois componentes (areia e fibra de coco) contribuíram com a vermiculita proporcionando também um sistema de enraizamento satisfatório ao processo de formação e desenvolvimento de raízes nas estacas de paricá. Isto leva em consideração a afirmativa de vários autores, quanto a importância da formulação de misturas de substratos nas quais se tentam obter um maior número possível de características favoráveis ao enraizamento e sobrevivência das estacas.

Para a variável número médio de raízes (Tabela 1) não ocorreu interação entre substrato e tempo de avaliação. Com relação ao substrato, as combinações de vermiculita+fibra de coco e vermiculita+fibra de coco+areia também propiciaram os melhores resultados diferindo da vermiculita+areia, com obtenção máxima de 12,92 e 12,85 raízes, respectivamente, com igualdade entre si, diferindo do substrato vermiculita+areia, que proporcionou o desenvolvimento de uma média de 5,13 raízes por estaca.

Para o efeito do tempo, a análise de regressão (Figura 3) também mostrou significância em função do tempo de avaliação. A análise revelou uma tendência de aumento do número médio de raízes com o passar do tempo, obtendo o máximo aos 20 dias (13,7 raízes), porém mostrou comportamento igual aos 25 e 30 dias.

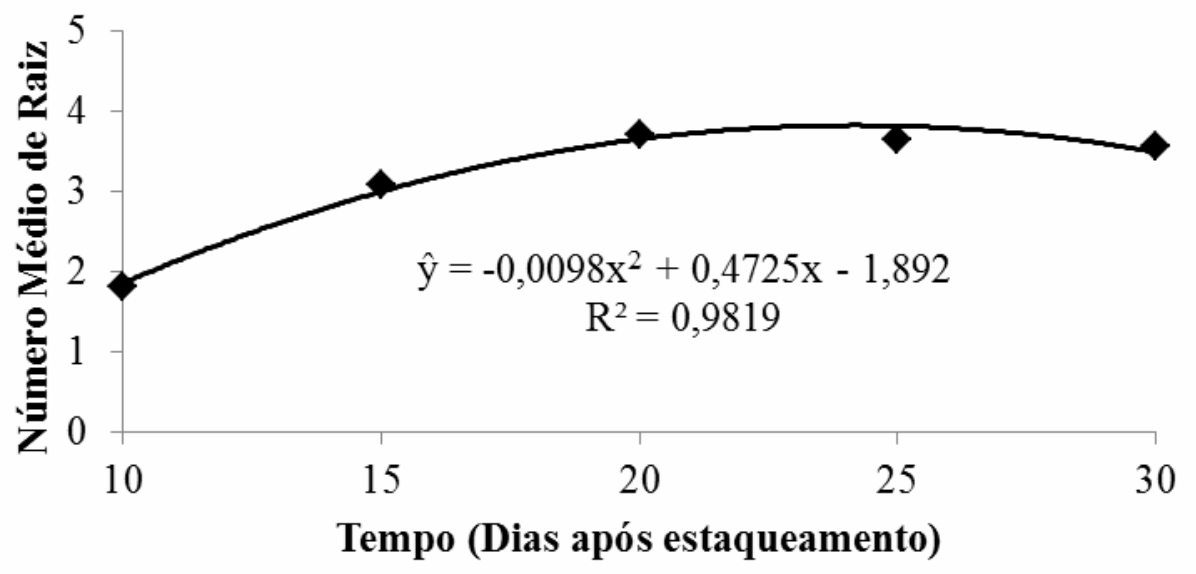

FIGURA 3 Número Médio de Raiz em função do tempo de avaliação

Vale destacar a importância não apenas do percentual de raiz formada nas estacas, mas também do desenvolvimento do sistema radicular. O número e comprimento de raízes formadas nas estacas são variáveis relevantes na produção das mudas. Nas estacas de paricá, o número máximo de raiz formado foi de 18 raízes, obtidas aos 20 dias, no substrato vermiculita+fibra de coco e o máximo de comprimento chegou a 4,25 centímetros, também nesta condição de substrato e tempo. Uma melhor resposta para estas variáveis indica que as mudas 
posteriormente formadas possuirão melhor desenvolvimento, uma vez que a melhoria da qualidade do sistema radicial suporta maiores chances de sobrevivência das mudas quando transplantadas para o campo.

Nas Figuras 4 e 5 são apresentados os resultados da análise de regressão para o percentual de estacas com calos (\%ECC), estacas brotadas (\%EB) e comprimento do broto (CB). Para essas variáveis houve diferença significativa ao nível de 5\% de probabilidade para \%EB, CB e \%ECC, apenas em função da primeira avaliação, que apresentou os menores valores nestas variáveis, os demais períodos tiveram comportamento iguais.

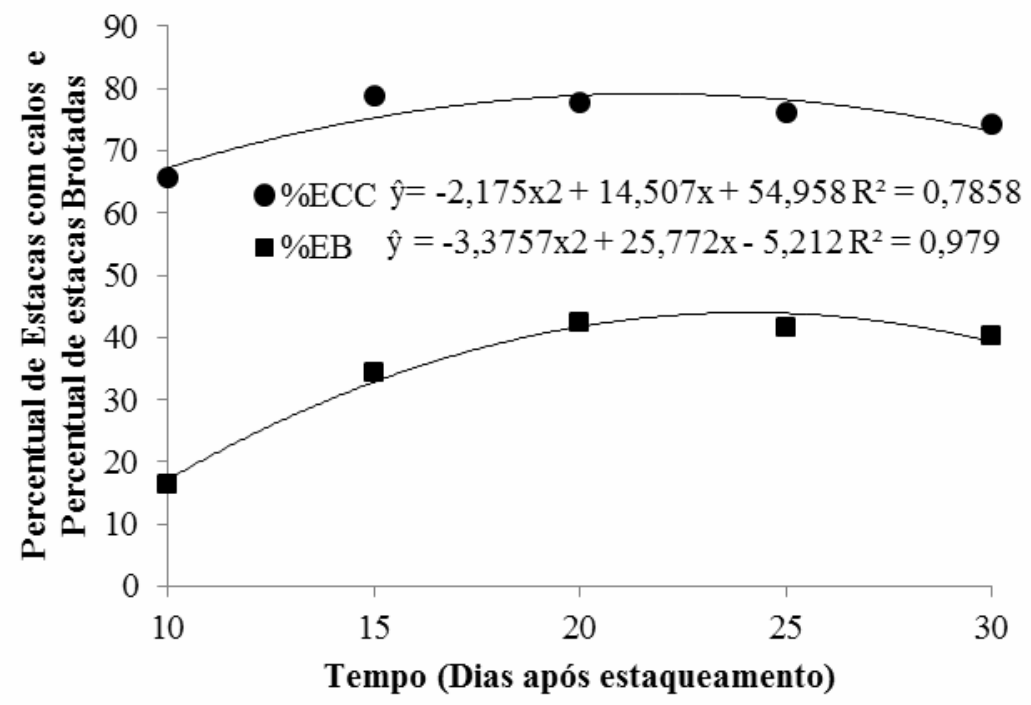

FIGURA 4 Evolução da percentagem de estacas com calos e percentagem de estacas brotadas em função do tempo de avaliação

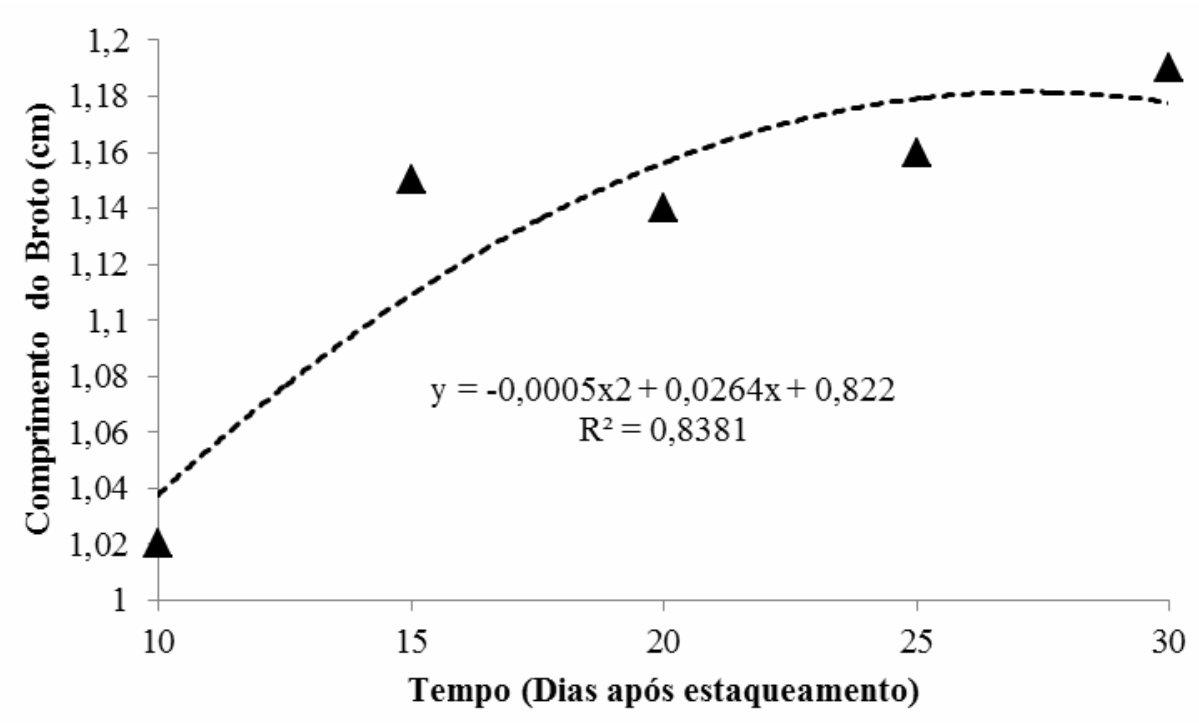

FIGURA 5 Comprimento do broto em função do tempo de avaliação

Em relação à formação de calos, a análise de regressão revelou um acentuado aumento no decorrer do tempo de avaliação. As estacas já apresentavam um desenvolvimento deste tecido desde os primeiros dias após o estaqueamento, 
atingindo aos 15 dias o percentual máximo (78,96\%), sem alteração até a última avaliação. Este cenário demonstra um grau de competência dos tecidos para o processo de diferenciação na base das estacas. A percentagem de calos apresenta um comportamento descendente no tempo, o que se deve em função da percentagem de enraizamento aumentar, diminuindo assim a quantidade de estacas com presença de calo apenas.

Resultados semelhantes foram observados por HERNANDEZ et al. (2013) ao estudarem o enraizamento de estacas de jequitibá-rosa (Cariniana estrellensis (Raddi) Kuntze), com e sem AIB. Entretanto, é possível notar, que os calos não estavam presentes em todas as estacas de paricá, portanto, como não foi feita uma relação entre estacas que formaram calos e estacas que enraizaram, a formação dos mesmos não pode ser considerada um pré-requisito para a formação de raízes, ou seja, os primórdios radiculares podem ter se originados de regiões com ou sem calos.

HARTMANN et al. (2011) apontam que, a rapidez na formação de calos muitas vezes determina o êxito do plantio de estacas em algumas espécies florestais. Porém, nem sempre isto está relacionado com a formação de raízes, como no caso das espécies de difícil enraizamento onde a formação de raízes pode ocorrer sobre o calo. No entanto, a formação do calo não é um indício da formação dos primórdios radiculares, já que são processos fisiológicos independentes.

Em estacas de pau-brasil (Caesalpinia echinata), ENDRES et al. (2007) sugerem que apesar do baixo enraizamento das estacas há potencialidade de formação de calos, que se mostrou favorável mesmo na ausência do fitorregulador. Isto pode ser indicativo de formação de raízes em longo prazo, que os autores indicam acima de 120 dias.

O processo de formação de raízes em paricá necessita de aplicação de AIB, que conforme ROSA \& PINHEIRO (2001), as concentrações devem variar entre 2,545 e 3,979 mg. $\mathrm{L}^{-1}$ em estacas juvenis. Dentro do contexto da aplicação das auxinas, BETTIOL NETO et al. (2006) relatam que a aplicação exógena do AIB pode promover um desbalanceamento das substâncias presentes internamente nas estacas, promovendo assim um favorecimento ao enraizamento pelo suplemento desta auxina, mas consequentemente, pode desfavorecer o crescimento das brotações.

Quanto ao comprimento dos brotos, os resultados mostraram um baixo desenvolvimento da parte aérea, atingindo em média 1,13 centímetros de comprimento. Essa observação permite considerar que a permanência das estacas nos substratos por mais de 20 dias pode ter sido prolongado, a ponto de comprometer o desenvolvimento da parte aérea. Pode inclusive ter prejudicado as outras estacas a emitirem brotações, com este tempo de permanência, uma vez que as estacas não receberam nenhum tratamento nutricional ao longo do tempo. Portanto, o tempo pode ter sido um fator importante ao baixo desenvolvimento da parte aérea, considerando que as reservas orgânicas presentes nas estacas, em sua maioria são assimiladas para produção de raízes.

O desenvolvimento de brotação nas estacas teve um comportamento semelhante ao enraizamento, no qual a análise de regressão mostrou significância em função do tempo. A evolução do enraizamento e da brotação nas estacas no decorrer do tempo teve um crescimento ascendente seguindo uma curva quadrática (Figura 6). 


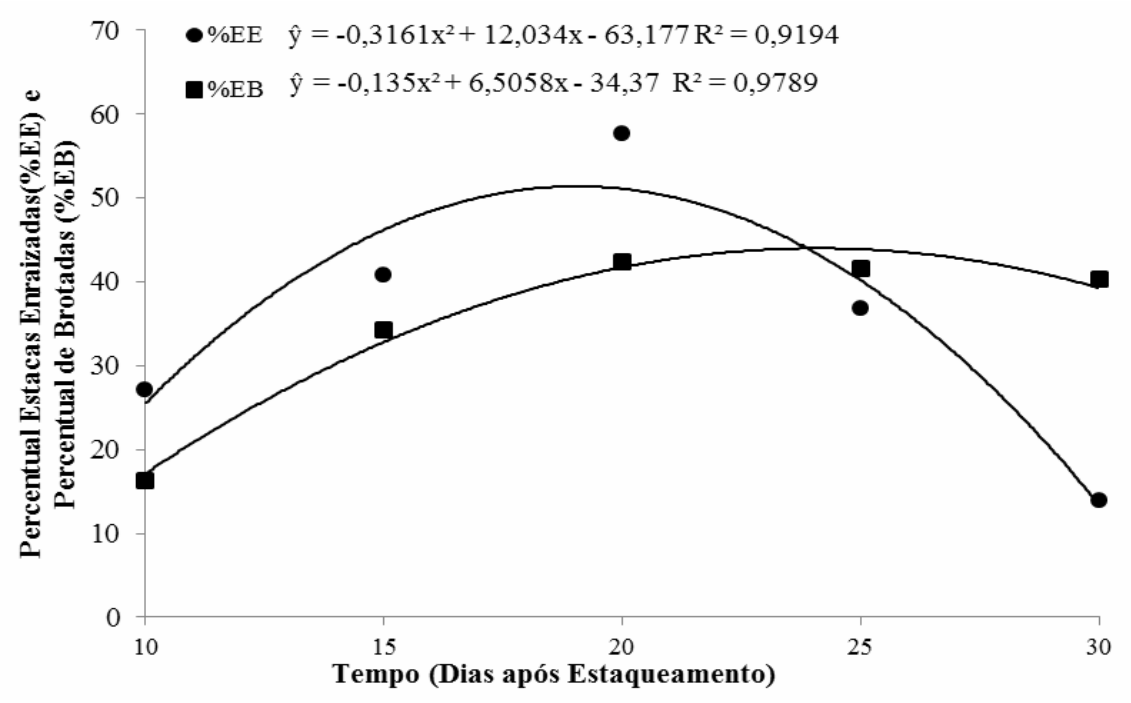

FIGURA 6 Evolução do percentual de estacas enraizadas (\%EE) e percentagem de estacas brotadas (\%EB) obtidas de mudas de paricá em função do tempo

A análise de regressão mostrou que apesar de não haver incremento no percentual de estacas brotadas a partir de 20 dias, o ponto máximo de estacas que emitiram brotações ocorreu aos 24 dias $(44,0 \%)$. Enquanto o percentual de enraizamento foi inferior a partir desse período, principalmente aos 30 dias onde ocorreu o menor percentual de enraizamento. O alcance máximo $(51,36 \%)$ de estacas enraizadas ocorreu aos 19 dias, com posterior redução.

A este resultado, pode-se inferir que provavelmente, como reflexo da maior formação de raízes nas primeiras avaliações, as estacas ao final do experimento passaram a desenvolver melhor as brotações. Isto foi positivo para o enraizamento das estacas, uma vez que as brotações durante o processo de enraizamento podem se constituir em drenos de fotoassimilados, que seriam utilizados no processo de indução e desenvolvimento de raízes, afetando negativamente o enraizamento de estacas.

A relação da formação de raiz e baixo desenvolvimento das brotações em estacas de paricá, pode sugerir, que fornecer condições nutricionais adequadas para favorece um maior desenvolvimento da parte aérea. Pois toda reserva orgânica contida na estaca, possivelmente foi consumida durante o processo rizogênico.

O tempo de permanência das estacas no ambiente de enraizamento não pode ser pré-determinado, porém pode variar com a espécie. Deste modo, uma boa alternativa para a otimização da estaquia é a possibilidade de redução desse tempo na casa de enraizamento. Isto pode diminuir os riscos de ocorrência de doenças ao longo do tempo face às condições propícias do ambiente, o que pode prejudicar o seu desenvolvimento ou ocasionar a morte da estaca.

De acordo com LIMA et al. (2011), a dessecação é uma das principais causas da morte caulinar. A ausência de raízes impede a absorção de água em quantidade suficiente, enquanto que as folhas e brotações continuam perdendo água por transpiração. Vale ressaltar, que neste experimento, todas as estacas que estavam mortas (13,9\%) no período final de avaliação (30 dias) apresentavam raízes.

O comportamento apresentado em relação ao fato de a maioria das estacas atingirem o máximo de enraizamento no período de 20 dias pode ter contribuído ENCICLOPÉDIA BIOSFERA, Centro Científico Conhecer - Goiânia, v.13 n.23; p. 12792016 
para a morte das estacas no decorrer do tempo. Pode-se pressupor que a partir deste período as estacas de paricá já podem ser submetidas aos demais processos de desenvolvimento da raiz e parte aérea, com controle de temperatura, luz, umidade e nutrientes que proporcionem maior crescimento do vegetal.

Em relação ao tempo de enraizamento das estacas, há relatos sobre o fato de que, as espécies apresentam períodos variáveis para indução de enraizamento. Em Caesalpinia echinata (pau-brasil), ENDRES et al. (2007) recomendaram que o tempo de permanência das estacas sob nebulização deve ser superior a 120 dias, visto que grande parte das estacas sobreviventes, não apresentaram calos ou raízes. Em estudos de enraizamento de segmentos nodais de teca (Tectona grandis L.), GEORGIN et al. (2014) identificaram que quando os segmentos são submetidos as maiores concentrações do fitorregulador AIB, estes desenvolveram maiores percentuais de calosidade em sua base aos 180 dias após estabelecimento em casa de vegetação.

MELO et al. (2011), ao analisaram o tempo necessário para o enraizamento de miniestacas de clones híbridos de Eucalyptus grandis, obtiveram o máximo potencial entre 10 a 20 dias, variando entre os clones estudados. Para cedro (Cedrella fissilis), XAVIER et al. (2003) observaram que 30 dias é o tempo médio suficiente para a permanência das estacas na casa de enraizamento. A definição da velocidade de enraizamento, otimiza o uso de estruturas de produção de mudas a partir da estaquia, inferindo sobre o melhor momento para retirada das estacas.

\section{CONCLUSÕES}

A vermiculita em combinação com fibra de coco é eficiente no enraizamento de estacas obtidas de mudas de paricá por proporcionarem as melhores condições para a formação e desenvolvimento de raízes nas estacas e por ocasionarem mais rapidamente a formação de raízes, com alcance em até 20 dias do máximo potencial de enraizamento.

\section{REFERÊNCIAS}

ARAMÉNDIZ-TATIS, H.; CARDONA-AYALA, C.; CORREAALVAREZ, E. Efecto de diferentes sustratos en la calidad de plántulas de berenjena (Solanum melongena L.). Revista Colombiana Ciencias Hortícolas, v. 7, n. 1, p. 55-61, 2013. Disponível em: <http://www.scielo.org.co/pdf/rcch/v7n1/v7n1a06.pdf>

BETTIOL NETO, J. E.; PIO, R.; BUENO, S. C. S.; BASTOS, D. C; SCARPARE FILHO, J. A. Enraizamento de estacas dos portas enxerto Araticum-de-terra-fria (Rollinia sp.), Araticum-mirim (Rollinia emarginata Schltdl.) para anonáceas. Ciência agrotécnica, v. 30 , n. 6, p. 1077-1082, 2006. Disponível em: <http://dx.doi.org/10.1590/S1413-70542006000600005>. doi: 10.1590/S141370542006000600005

BORGES, S.R.; XAVIER, A.; OLIVEIRA, L. S. de; MELO, L. A. de; ROSADO, A. M. Enraizamento de miniestacas de clones híbridos de Eucalyptus globulus. Revista Árvore, v. 35, n. 3, p. 425-434, 2011. Disponível em: http://dx.doi.org/10.1590/S0100-67622011000300006 doi: 10.1590/S010067622011000300006 
CARDOSO, C.; YAMAMOTO, L. Y.; PRETI, E. A.; ASSIS, A. M.; NEVES, C. S. V. J.;ROBERTO, S. R. AIB e substratos no enraizamento de estacas de pessegueiro 'Okinawa' coletadas no outono. Semina: Ciências Agrárias, v. 32, n. 4, p. 13071314, 2011. Disponível em: <http://dx.doi.org/10.5433/1679-0359.2011v32n4p1307> doi: 10.5433/1679-0359.2011v32n4p1307

CASTOLDI, R.; GOMES, R. F.; CHARLO, H. C. O.; MELO, D. M.; BRAZ, L. T. Performance of cucumber hybrids cultivated in coconut fiber and soil. Horticultura Brasileira, v. 32, n. 1, p. 86-90, 2014. Disponível em: <http://dx.doi.org/10.1590/S0102-05362014000100014> doi: 10.1590/S010205362014000100014

DIAS, P.C.; OLIVEIRA, L.S.; XAVIER, A.; WENDLING, I. Estaquia e miniestaquia de espécies florestais lenhosas do Brasil. Pesquisa Florestal Brasileira, v. 32, n. 72, p. 453-462, 2012. Disponível em: <http://dx.doi.org/10.4336/2012.pfb.32.72.453> doi: 10.4336/2012.pfb.32.72.453

DUCKE, A. As leguminosas da Amazônia brasileira: notas sobre a flora neotrópica - II. Belém: Instituto Agronômico do Norte. Boletim Técnico, 18, 1949. $248 p$.

ENDRES, L.; MARROQUIM, P. M. G.; SANTOS, C. M. dos.; SOUZA, N. N. F. de. Enraizamento de estacas de pau-brasil (Caesalpinia echinata Lam) tratadas com ácido indol butírico e ácido naftalacético. Ciência Rural, v. 37, n. 3, p. 886-889, 2007. Disponível em: <http://dx.doi.org/10.1590/S0103-84782007000300046> doi: $10.1590 / \mathrm{S} 0103-84782007000300046$

GARAY, C. R. E.; BOGARIN, N. B. G.; OVIEDO, V. R. S. Producción de mudas de tomate en el sistema flotante. Investigación Agraria, v. 16, n. 2, p. 129-135, 2014.

GEORGIN, J.; BAZZOTI, R.; PERRANDO, E. Indução ao enraizamento de estacas de teca (Tectona grandis L.). REGET, v. 18 n. 3, p.1246-1256, 2014. Disponível em: < http://dx.doi.org/10.5902/2236117014537>. doi: 10.5902/2236117014537

haRTMANN, H. T.;KESTER, D. E.; DAVIES JR., F. T.; GENEVE, R. L. Plant propagation: principles e practices. 8 ed. New Jersey: Prentice Hall, 2011. 915p.

HERNANDEZ, W.; XAVIER, A.; PAIVA, H. N.; WENDLING, I. Propagação vegetativa do jequitibá-rosa (Cariniana estrellensis (Raddi) KUNTZE) por estaquia. Revista Árvore, v.37, n.5, p.955-967, 2013. Disponível em: <http://dx.doi.org/10.1590/S010067622013000500018>. doi: 10.1590/S0100-67622013000500018

KOYAMA, R.; ASSIS, A. M.; CARDOSO, C.; MORITZ, A.; ORTIZ, T. A.; ROBERTO, R. S. Enraizamento de estacas de lichieira tratadas com ácido indolbutírico e substratos. Revista Brasileira de Ciências Agrárias Brazilian Journal of Agricultural Sciences, v. 9, n 3, p.384-388, 2014. Disponível em: <http://www.agraria.pro.br/sistema/index.php>. doi: 10.5039/agraria.v9i3a3767 
LIMA, D. M.; BIASI, L. A.; ZANETTE, F.; ZUFFELLATO-RIBAS, K. C.; BONA, C.; MAYER, J. L. S. Capacidade de enraizamento de estacas de Maytenus muelleri Schwacke com a aplicação de ácido indol butírico relacionada aos aspectos anatômicos. Revista Brasileira de Plantas Medicinais, v.13, n. 4, p. 422-438, 2011. Disponível em: <http://dx.doi.org/10.1590/S1516-05722011000400008>. doi: $10.1590 /$ S1516-05722011000400008

MARTINS, C. C.; BOVI, M. L. A.; SPIERING, S. H. Umedecimento do substrato na emergência e vigor de plântulas de pupunheira. Revista Brasileira de Fruticultura, v. 31, n. 1, p. 224 - 230, 2009. Disponível em: <http://dx.doi.org/10.1590/S010029452009000100031 >. doi: 10.1590/S0100-29452009000100031

MELO, L. A. de; XAVIER, A.; PAIVA, H. N. de; BORGES, S. R. Otimização do tempo necessário para o enraizamento de miniestacas de clones híbridos de Eucalyptus grandis. Revista Árvore, v.35, n.4, p.759-767, 2011. Disponível em: <http://dx.doi.org/10.1590/S0100-67622011000500001>. doi: 10.1590/S010067622011000500001

OLIVEIRA, M. C de.; RIBEIRO, J. F.; RIOS,M. N. da. S.; REZENDE, M. E. Enraizamento de estacas para produção de mudas de espécie nativas de matas de galeria. Recomendação Técnica, 41. Brasília, DF. Outubro, 2001. 4p.

ROSA, L. dos S; PINHEIRO, K. A. O. Propagação vegetativa de estacas de paricá (Scizolobium amazonicum Huber Ex. Ducke) obtidas de material juvenil e imersas em ácido indol-3-butírico. Revista de Ciências Agrárias, v. 36, n. 35, p. 79-88, 2001.

SILVA, R. B. G. da; SIMÕES, SILVA, D.; M. R. da. Qualidade de mudas clonais de Eucalyptus urophylla $\times$ E. grandis em função do substrato. Revista Brasileira de Engenharia Agrícola e Ambiental, v.16, n.3, p.297-302, 2012. Disponível em: <http://dx.doi.org/10.1590/S1415-43662012000300010>. doi: 10.1590/S141543662012000300010

XAVIER A.; WENDLING I.; SILVA. R. L. Silvicultura clonal: princípios e técnicas. ed. UFV, Viçosa, MG, 2009. 272 p.

XAVIER, A.; SANTOS, G. A. dos.; WENDLING, I.; OLIVEIRA, M. L. Propagação vegetativa de cedro-rosa por miniestaquia. Revista Árvore, v.27, n.2, p.139-143, 2003. Disponível em: <http://dx.doi.org/10.1590/S0100-67622003000200003>. doi: $10.1590 /$ S0100-67622003000200003 